Heredity (1982), 48 (2), 321-326

(C) 1982. The Genetical Society of Great Britain

\title{
THE GENETICAL SOCIETY
}

\section{ABSTRACTS of papers presented at the HUNDRED AND NINETY- FIFTH MEETING of the Society, held on 13th and 14th November, 1981, at UNIVERSITY COLLEGE LONDON}

\section{GENETIC ORGANIZATION OF THE SEP-ENVA GENE CLUSTER IN ESCHERICHIA COLI}

\author{
G. F. HATFULL, K. J. BEGG, N. F. SULLIVAN, V. KAGAN-ZUR, V. DERBYSHIRE \\ AND W. D. DONACHIE \\ Department of Molecular Biology, University of Edinburgh, King's Buildings, \\ Mayfield Road, Edinburgh EH9 3JR
}

The genome of $E$. coli has several obvious clusters of genes located around the chromosome. Each cluster consists of a contiguous group of genes of related function organised into more than one operon. Besides those clusters involving control of transcription and translation there is a group of at least 10 genes which maps between leu and azi at $2^{\prime}$ on the $E$. coli map. The genes of this cluster (sep-envA) affect various aspects of cell envelope growth and function and include five which are directly involved with cell division. We have been analysing the right hand end of this cluster which contains genes involved in cell division (the fts $Q$ fts $A$ $f t s Z$ envA region) primarily using the techniques of gene fusion to assign promoter locations and strengths to a $2.2 \mathrm{~kb}$ EcoRI segment within this region. Possible interactions between adjacent transcriptional units will be discussed together with their possible implications in the control of cell division.

\section{THE THIRD GENE OF THE NITRATE ASSIMILATION GENE CLUSTER OF ASPERGILLUS NIDULANS IS INVOLVED IN NITRATE UPTAKE}

\author{
A. G. BROWNLEE and H. N. ARST, Jr.
}

Department of Genetics, University of Newcastle upon Tyne, NEI TRU

The genes involved in nitrate assimilation in the fungus Aspergillus nidulans are clustered in the order: $c r n A-$ niiA-niaD (Tomsett and Cove, Genet. Res. 34, 19, 1979). niaD and nii $A$ are the structural genes for nitrate and nitrite reductases, respectively (MacDonald and Cove, Eur. J. Biochem., 47, 107, 1974; Rand and Arst, Molec. gen. Genet., 155, 67, 1977). Mutations in $\mathrm{cmA}$ confer resistance to chlorate and bromate toxicities without affecting utilisation of nitrate or nitrite (Tomsett and Cove, Genet. Res., 34, 19, 1979). Cove proposed that $c r n A$ might specify a nitrate permease but early attempts to demonstrate differences in nitrate uptake between $\mathrm{cmA}^{-}$and wild-type strains were unsuccessful (see Tomsett, Ph.D. Thesis, University of Cambridge, 1977).

We have now succeeded in demonstrating a marked defect in nitrate uptake in $\mathrm{crnA}^{-}$ strains, using young mycelia. In older mycelia no differences between $\mathrm{crn} A^{-}$and wild-type strains with regard to nitrate uptake are observable. In addition, strains carrying a $p p p A^{-}$ mutation (Hankinson, $J$. Bacteriol., 117, 1121, 1974) are partially protected against nitrate toxicity by a $\mathrm{cmA} \mathrm{A}^{-}$mutation, providing further evidence for a defect in nitrate uptake. In $c m A^{+}$strains no nitrate uptake is detectable in the absence of nitrate reductase activity. As levels of nitrate reductase activity exceed measured nitrate uptake rates by several-fold, it seems likely that nitrate uptake in $\boldsymbol{A}$. nidulans proceeds by facilitated diffusion (possibly involving the $c r n A$ gene product) driven by intracellular nitrate assimilation. 


\title{
THE USE OF DELETION MUTATIONS TO DETERMINE PROBABLE TRANSCRIPT SIZE IN THE PROLINE CATABOLISM GENE CLUSTER OF ASPERGILLUS NIDULANS
}

\author{
K. K. SHARMA and H. N. ARST, JR.
}

\section{Department of Genetics, University of Newcastle upon Tyne, NE1 7RU}

The genes involved in L-proline catabolism in the fungus Aspergillus nidulans are clustered in the order: prnA-prnD-Cis-acting regulatory region-prnB-prnC (Arst and MacDonald, Nature, 254, 26, 1975; Arst and MacDonald, Molec. gen. Genet., 163, 17, 1978; Arst, Jones and Bailey, Genet. Res., 38, 171, 1981). prnA is probably a positive acting regulatory gene mediating proline induction whereas $\operatorname{prn} B, p r n D$ and $p r n C$ are the structural genes, for proline permease, proline oxidase and $\Delta^{1}$-pyrroline-5-carboxylate (P5C) dehydrogenase, respectively (Arst, MacDonald and Jones, J. gen. Microbiol., 116, 285, 1980; Jones, Arst and MacDonald, Current Genetics, 3, 49, 1981). Eight deletion mutations beginning in $p r n D$ and ending in $p r n B$ have been selected, and all reduce, but do not abolish, expression of $p r n C$ as judged from diploid complementation tests and P5C dehydrogenase assays (Arst and MacDonald, Molec. gen. Genet., 163, 17, 1978; Arst, Jones and Bailey, Genet. Res., 38, 171, 1981). This finding was interpreted to suggest that expression of prnC occurs both via a prnB prnC dicistronic messenger initiated in the $c i s$-acting regulatory region and via an overlapping messenger(s) which might be mono-, tri- or tetracistronic.

We have now selected a deletion which extends from before or within prnA to within prnB. The loss of prnA function precludes assessment of its effects on $p r n C$ expression from P5C dehydrogenase levels but diploid complementation responses are identical to those of the deletion mutations extending from within $p r n D$ to within prnB. This eliminates the possibility that the overlapping prnC messenger be tricistronic. As this deletion fails to recombine with any of the twenty $\mathrm{prnA}^{-}$point mutations tested to date, it is possible (but by no means established) that it extends beyond the prnA gene on the leftward side. If so, the overlapping prnC messenger is also not tetracistronic.

\section{THE HISTIDINE DICARBOXYLASE GENE COMPLEX ON CHROMOSOME 2 OF THE MOUSE}

\author{
S. A. M. MARTIN and GRAHAME BULFIELD \\ Department of Genetics, University of Leicester and Genetics Group, \\ ARC Poultry Research Centre, Roslin, Edinburgh
}

A large number of structural and regulatory genes controlling enzyme levels have been identified in the mouse. Most regulatory loci map near or within the structural gene forming a "gene complex". Mouse kidney histidine decarboxylase (HDC; EC 4.1.1.22) is regulated by at least three hormones and therefore provides an excellent system to study genetic regulation of gene expression. We have seven distinct HDC phenotypes among inbred strains of mice and wild mice from several locations. Analysis of these using biochemical and genetical techniques will allow us to investigate the structure of the gene complex for the enzyme. The difference in the activity between strains with high levels $(\mathrm{DBA} / 2$ and $\mathrm{C} 3 \mathrm{H} / \mathrm{He}$ ) and the most commonly occurring phenotype (C57BL/10) shows Mendelian segregation. Heat stability analysis has revealed a difference at the HDC structural locus between these strains. Analysis of recombinant inbred lines constructed from high and low strains has shown perfect co-segregation of activity with heat-stability phenotypes and has permitted mapping of the locus to chromosome 2 . In low activity strains HDC is induced by up to 20 fold by oestrogen whereas the enzyme from high activity strains is non-inducible. We are currently investigating whether the locus responsible for oestrogen-inducibility maps within the gene complex on chromosome 2.

\section{GENE TRANSFER INTO THE MOUSE GERM-LINE}

\section{E. LACY and F. COSTANTINI}

\section{Department of Zoology, University of Oxford, South Parks Road, Oxford, OX1 3PS}

DNA from a bacteriophage lambda clone ( $\lambda$ RBG2), containing the rabbit adult $B$-globin gene and a B-like pseudogene, has been introduced into mouse germ-line DNA by microinjec- 
tion into the pronuclei of fertilized mouse eggs. Fifty-one mice were obtained from the injected eggs, and 24 of these were screened for the presence of rabbit B-globin gene sequences by Southern blot hybridizations to DNA extracted from liver biopsy samples. Nine of these 24 mice (38 per cent) contain $\lambda$ RBG2 sequences in numbers ranging from one to two up to 20-50 copies per average liver cell. The majority of the $\lambda$ RBG2 copies in the mouse DNAs appear to be intact and to be integrated into mouse chromosomes in tandem head to tail arrays. Chromosomal integration of the rabbit sequences has been demonstrated directly in one mouse by performing in situ hybridizations to metaphase chromosome spreads prepared from peripheral blood. To determine whether germ-line cells, as well as somatic cells, had acquired copies of the injected rabbit DNA fragment, six of the positive mice were tested for the transmission of $\lambda$ RBG2 sequences to their progeny. All six were found to transmit rabbit B-globin gene sequences to a fraction of their progeny.

\title{
COORDINATE INDUCTION BY ANDROGENS?
}

\author{
J. A. SIMONS and J. G. M. SHIRE \\ Biology Department, University of Essex
}

The submaxillary glands of C57BL and BALB/c mouse strains and their recombinant lines are being used to develop a model system for investigating the hormonal control of gene expression. In vitro translations of mouse submaxillary gland RNA in a rabbit reticulocyte system were used to monitor induction of RNA synthesis by testosterone propionate treatment. Differences in induction exist between the two parental strains. Protein samples were analysed in an SDS-urea 5-20 per cent gradient PAGE system. Gels run with proteins and stained with Coomassie blue show a high molecular weight protein which occurs after induction in C57BL and in no other line, neither parental nor recombinant. This pattern is identical to that found for sex differences in kidney weight and for testis size. These results suggest a basic difference in androgen response in three target organs by C57BL when compared to $\mathrm{BALB} / \mathrm{c}$.

\section{STABILITY OF CLONED GENES IN YEAST GROWN IN CHEMOSTAT CULTURE}

\author{
R. M. WALMSLEY and S. G. OLIVER
}

\section{Department of Biochemistry, University of Manchester Institute of Science and Technology, P.O. Box 88, Manchester, M60 10D}

The stability of the $L E U 2$ gene of Saccharomyces cerevisiae has been examined when reinserted into yeasts on a variety of different vectors which provide both episomal and chromosomal locations for the gene. The loss of the gene was monitored in long-term, glucose-limited continuous culture. Under these conditions there is no selection for leu ${ }^{+}$cells. The effect of the insertion of the various vectors on the maximum specific growth rate of the host strain (AH22) was determined in the fermentor using the wash-out method.

The $L E U 2$ gene was inserted into the ribosomal array where it had no measurable effect on the growth rate of the cell. The proportion of $\mathrm{leu}^{-}$cells in the culture varied between 0.15 and 2.6 per cent, there being no accumulation of $\mathrm{leu}^{-}$cells. Two replicative vectors which contained all (pjDB219) or part (AT416) of the yeast $2 \mu$-circular plasmid reduced the maximum specific growth rate of the host by 17 and 26 per cent respectively. AT416 was lost from the culture at a rate of $10^{-2}$ generation $^{-1}$ and $l e u^{-}$cells accumulated at the rate predicted by the selection for their increased growth rate. Cultures carrying pjDB219 also lost the plasmid at a high rate but $\mathrm{leu}^{-}$cells did not accumulate, their proportion stabilising at $c a .6$ per cent and $c a .10$ per cent for two independent $\mathrm{AH} 22$ transformants. A plasmid carrying $L E U 2$, the ARS1 replicator and the centromere region of chromosome III (CEN3) had no effect on the growth rate of $\mathrm{AH} 22$ but was lost at a rate of $10^{-2}$ generation $^{-1}$, with $\mathrm{leu}^{-}$cells accumulating. 


\title{
RESISTANCE TO 5-FLUOROINDOLE IN COPRINUS
}

\author{
D. VEAL and L. A. CASSELTON
}

\author{
Department of Plant Biology \& Microbiology, Queen Mary College, \\ University of London, Mile End Road, London E1 ANS
}

5-fluoroindole (5FI), an analogue of indole, is converted intracellularly to 5-fluorotryptophan (5FT) an effective feed back inhibitor of the first enzyme in the tryptophan biosynthetic pathway, anthranilate synthetase. Selection for resistance to 5FI yielded mutants with altered regulation of the tryptophan pathway as measured by activities of the two key enzymes anthranilate synthetase and tryptophan synthetase. Mutations mapped at 5 loci designated iar-1-iar-5. iar-5 mutations map in the structural gene for anthranilate synthetase and result in a feed back resistant enzyme. The other loci appear to have regulatory functions. The commonest class of mutants recovered, iar-2 mutants, have wild type levels of pathway enzymes but secrete large amounts of anthranilic acid produced as the degradation product of tryptophan, not the precursor. The rate of flux through the pathway is apparently increased without a change in enzyme levels. iar-1 and iar-3 mutants have elevated pathway enzymes and overproduce tryptophan, iar-1 acts on the early common aromatic pathway because it confers resistance to analogues of other aromatic amino acids whereas iar-3 only acts on that part of the pathway specific to tryptophan biosynthesis. iar-4 mutations have the odd effect of depressing the wild type level of tryptophan synthetase activity with concomitant elevation of anthranilate synthetase activity. Resistance is, therefore, caused by dilution of $5 \mathrm{FI}$ by accumulated indole glycerol phosphate, the normal substrate for tryptophan synthetase.

\section{INVESTIGATION OF GENE DOSAGE EFFECTS AND FUNCTIONAL REDUNDANCY OF TRNA IN MISSENSE SUPPRESSION IN COPRINUS}

\author{
K. H. VOUSDEN and L. A. CASSELTON \\ Department of Plant Biology \& Microbiology, Queen Mary College, \\ University of London, Mile End Road, London E1 4NS
}

A number of suppressor gene mutations have been described in Coprinus which show a gene dosage effect. In homozygous diploids or diploids heterozygous for non-allelic sup ${ }^{+}$ mutations the suppressor phenotype is expressed but in diploids heterozygous for a single sup $^{+}$mutation the sup ${ }^{+}$phenotype is not expressed. It has been suggested that these dosage effects define $\sup ^{+}$genes involving modified tRNAs which suppress missense mutations. If this interpretation is correct, then in $\sup ^{+} /$sup $^{-}$heterozygotes a low level of translational correction should still occur even though the level of enzyme activity may be too low to support a visible amount of growth. This has now been confirmed using acul mutants. Cell free extracts of acul.4 mutants lack any detectable activity of acetyl CO-A synthetase. In diploids homozygous for either of two non-allelic sup ${ }^{+}$mutations sup a $4 \cdot 1^{+}$or $\sup a 4 \cdot 2^{+}$, some 21-24 per cent of wild type enzyme activity was restored and in diploids heterozygous for both sup mutations (sup a $4 \cdot 1^{+} / \sup ^{-}$; sup a $4 \cdot 2^{+} /$sup $^{-}$) there was 23 per cent of wild type activity. In diploids heterozygous for either one sup mutation a low level of enzyme activity was detectable (3-6 per cent of wild type), clear evidence of sup ${ }^{+}$function.

Extensive selection for suppression of acul.4 revealed only two suppressor genes. The two "suppressed" enzymes were indistinguishable one from another on the basis of $\mathrm{Km}$ and thermal stability but were less thermostable than the wild type enzyme. This indicates translational correction to an alternative amino acid by two redundant isoaccepting tRNA species.

\section{BIOCHEMICAL CHARACTERIZATION OF THE ACIAC LOCUS CONTROLLING CYANOGENIC GLUCOSIDE PRODUCTION IN WHITE CLOVER (TRIFOLIUM REPENS L)}

\author{
D. B. COLLINGE and M. A. HUGHES
}

Department of Genetics, University of Newcastle upon Tyne

Plants which do not contain cyanogenic glucoside lack at least two enzymes in the biosynthetic pathway. (Hughes and Conn, Phytochemistry, 15, 697-701, 1976). In order to 
investigate the protein differences between $\boldsymbol{A c} / \boldsymbol{A c}$ and $a c / a c$ plants, studies have been undertaken to develop an in vitro system for cyanogenic glucoside production. A microsomal fraction from plants of genotype $A c / A c$ will utilize the amino acid precursors in the presence of NADPH, a similar fraction from $a c / a c$ plants lacks this activity. The protein components of the particulate fraction have been investigated using SDS polyacrylamide gel electrophoresis.

\section{THE EFFECTS OF AN AZO-DYE IN DROSOPHILA MELANOGASTER}

\section{S. THOMSON, P. J. HANNA and J. BLUNCK}

Division of Biological and Health Sciences, Deakin University, Victoria 3217, Australia

Investigations to determine whether labelled aromatic aminoazo dye bound to polytene chromosomes of $D$. melanogaster, particularly in the regions of the heterochromatically located rRNA genes, gave negative results. However it was found that labelled dye showed a clear selective killing of male flies and was manifest during pupal development. Furthermore, it appeared that the selective killing only occurred in males which possessed a complete $Y$ chromosome (i.e., $\mathrm{Y}^{\mathrm{S}}$ and $\mathrm{Y}^{\mathrm{L}}$ were attached) as well as an undeleted bobbed locus on the $\mathrm{Y}$ chromosome.

\section{STRUCTURE AND EXPRESSION OF GLOBIN GENES}

\section{R. A. FLAVELL}

Laboratory of Gene Structure and Expression, National Institute for Medical Research, Mill Hill, London NW7

In the past few years structural studies on cloned globin genes have taught us much about the structure and linkage arrangement of these genes. In man, for example, the genes are present on two linkage groups with the $\beta$-family on chromosome 11 and the $\alpha$-family on chromosome 16 . The $\beta$-related globin genes are present on the chromosome in the order $5^{\prime} \varepsilon$ (embryonic) $\mathrm{G} \gamma \mathrm{A} \gamma$ (foetal) $\delta$ and $\beta$ (adult) $3^{\prime}$. We have cloned about $150 \mathrm{~kb}$ of this region as overlapping cosmid clones and have used these to study the arrangement of the genes, pseudogenes and repeated sequences.

Studies on globin gene expression have now been performed using an SV40 based system. A given globin gene is linked to an SV40 plasmid and introduced into Hela cells by calcium phosphate co-precipitation. After $48 \mathrm{~h}$ globin gene expression can be detected as shown by $\mathrm{S} 1$ nuclease transcript mapping. We have used this assay to define the in vivo promotor for the rabbit $\beta$-globin gene.

This system has proved invaluable for the study of the molecular basis of human $\beta$-globin gene defects. $A \beta$-globin gene fragment from a patient with $\beta^{+}$thalassaemia has been linked to this vector and its expression studied in Hela cells. This gene is transcribed normally but spliced abnormally as a consequence of a point mutation in the first intron of the $\beta$-globin gene. These results explain the molecular defect in this form of $\beta^{+}$thalassaemia and will be discussed in detail.

\section{TISSUE SPECIFIC EXPRESSION OF MOUSE $\alpha$-AMYLASE GENES}

\section{O. HAGENBÜCHLE, U. SCHIBLER, R. YOUNG, M. TOSI and P. K. WELLAUER \\ Swiss Institute for Experimental Cancer Research, Lausanne}

Two $\alpha$-amylase genes, $A m y-1^{a}$ and $A m y-2^{a}$ are expressed in the mouse strain $A / J$. $A m y-1^{a}$ which is present in one copy per haploid genome specifies the tissue specific $\alpha$-amylase mRNAs found in liver and salivary gland. These two mRNAs which accumulate to different extents in the two tissues contain identical coding-and-3' noncoding regions but differ in their $5^{\prime}$-terminal noncoding segments. The two cap sites reside $3 \mathrm{~kb}$ apart in $A m y-1^{\mathrm{a}}$. Tissue specific splicing has to occur for the production of these two mRNAs. S1 analysis of nuclear and in vitro transcripts suggest a model on which tissue specific promoters govern the expression of 
this gene. The two apparently identical $A m y-2^{\mathrm{a}}$ genes present in the mouse genome code for the $\alpha$-amylase mRNA accumulating in the pancreas. This RNA differs in 11 per cent of its nucleotide sequence from its salivary gland and liver counterparts.

\title{
CONTROL OF SEGMENTAL DEVELOPMENT IN DROSOPHILA BY THE BITHORAX GENE CLUSTER
}

\author{
E. B. LEWIS
}

\author{
Division of Biology, California Institute of Technology, Pasadena, CA. U.S.A.
}

Differentiation of thoracic and abdominal segments of Drosophila appears to be primarily under the control of a large gene cluster, or bithorax gene complex (BX-C), comprising a minimum of nine recessive loss-of-function genes. The entire cluster mimics a multiple allelic series owing to the existence of polar position effects. Individual genes of the cluster control the level of development of specific types of segmental structures and cooperation of several genes is required to effect the transformation of one segment, or even a portion thereof, into another. Four cis-regulatory regions have been identified by means of dominant gain-offunction mutants. Control of bithorax gene function appears to be mediated by the response of such cis-regulatory regions to gradients in repressor-like substances elaborated by transregulatory genes. If recurrent tandem gene duplication and mutation is responsible for the present state of $\mathrm{BX}-\mathrm{C}$, then the cluster may have played a major role into the phylogeny of the arthropods.

(Work supported by USPHS grant HD 06331.)

\section{ANTIBODY GENES: THEIR ARRANGEMENT AND REARRANGEMENT}

\author{
H. V. HUANG \\ Division of Biology, California Institute of Technology, Pasadena, CA. U.S.A.
}

$A$ major portion of the vertebrate immune response is determined by the antibody multigene families. Antibodies are encoded by three multigene families $\mathrm{K}$ and $\lambda$ encode light (L) chains, and $\mathrm{H}$ encodes the heavy chains. $\mathrm{L}$ chain genes are composed of three discrete gene elements: $V_{L}$ (variable), $J_{L}$ (joining) and $C_{L}$ (constant). Heavy chains genes constitute similar gene elements, but, additionally, have $\mathrm{D}$ (diversity) gene segments. Antibody genes elements undergo two types of DNA rearrangements. Variable-gene formation joins the $\mathrm{V}_{\mathrm{L}}$ to $J_{L}$, and $V_{H}, D$, to $J_{H}$ gene segments into uninterrupted sequences to give functional, expressible $\mathrm{H}$ and $\mathrm{L}$ genes. Class switching, specific to the $\mathrm{H}$ chain family, allows one $\mathrm{C}_{\mathrm{H}}$ gene segment to be replaced by a second. I will discuss our knowledge about the mechanisms of these DNA rearrangements, and consider the known sources of antibody diversity.

\section{FUNCTIONAL ASPECTS OF H-2 GENE PRODUCTS \\ ELIZABETH SIMPSON \\ Transplantation Biology Section, Clinical Research Centre, Harrow}

H-2 was originally discovered by Gorer and Snell as a histocompatibility locus in mice. Subsequent work has shown that $\mathrm{H}-2$ is actually a nest of closely linked loci in chromosome 17 and that its homologue exists in all mammals. The principal gene products are two different types of glycoproteins known as class I and class II molecules which are incorporated into cell surface membranes. One remarkable feature of both types of H-2 molecules is their extraordinary polymorphism. This is almost certainly a reflection of survival value, probably in relation to the ability to maintain immune response to intracellular pathogenic organisms, for example, viruses. This conclusion has come from a series of findings characterised by "H-2 restriction", that is, that T lymphocytes, which are the main regulators of the immune response and an important part of the effector arm, can only "see" extrinsic antigen (e.g., viruses) in the context of self $\mathrm{H}-2$ molecules. T lymphocytes thus have receptors with specificity for self $\mathrm{H}-2$ (class I or class II) molecules as well as for the extrinsic antigen. The different types of H-2 molecules appear to act as "guides" for different functional subsets of T lymphocytes. 
(C) 1982. The Genetical Society of Great Britain

List of Names and Addresses of Officers of the Genetical Society 1981-1982

BAUMBERG, Dr S., (Senior Secretary), Genetics Department, The University of Leeds, Leeds LS2 9JT

BOBROW, Dr M., Dept. of Medical Genetics, Oxfordshire Area Health Authority, Old Road, Headington, Oxford OX3 7LE

BOWNES, Dr M., Department of Molecular Biology, The University of Edinburgh, Kings Buildings, Mayfield Rd., Edinburgh EH9 3JR

BULFIELD, Dr G., ARC Poultry Research Centre, Roslin, Midlothian EH25 9PS

BURNET, Dr B., (Junior Secretary), Department of Genetics, University of Sheffield, S10 2TN

CHANDLEY, Dr A. C., (Vice-President), MRC Clinical and Population Cytogenetics Unit, Western General Hospital, Edinburgh EH4 2XU

CHARLESWORTH, Dr B., Department of Biology, University of Sussex, Biology Building, Falmer, Brighton, BN1 9QG

CLARKE, Prof B. C., FRS, (Editor of "Heredity" and Vice-President), Genetics Department, The University of Nottingham, Nottingham NG7 2RD

DA VIES, Prof D. R., (Editor of "Heredity"), John Innes Institute, Colney, Lane, Norwich NR4 7UH

DOVER, Dr G. A., Department of Genetics, University of Cambridge, Downing Street, Cambridge CB2 3EH

GALE, Dr M. D., Plant Breeding Institute, Maris Lane, Trumpington, Cambridge CM2 2LQ

HARRISON, Dr B., (Archivist), John Innes Institute, Colney Lane, Norwich NR4 7UH

HILL, Dr W. G., Department of Genetics, The University of Edinburgh, Kings Buildings, West Mains Rd., Edinburgh EH9 3JN

JINKS, Prof J. L., FRS, (President), Department of Genetics, The University of Birmingham, PO Box 363, Birmingham B15 2TT

PARRY, Dr J., Department of Genetics, University College of Swansea, Singleton Park, Swansea SA2 8PH

POVEY, Dr M. S., Galton Laboratory, University College, Wolfson House, 4 Stephenson Way, London NW1 2HE

REES, Prof H., FRS, (Vice-President), Department of Agricultural Botany, Institute of Rural Science, Penglais, Aberystwyth SY23 3DD

SAUNDERS, Dr J. R., Microbiology Department, Life Sciences Building, University of Liverpool, Liverpool L69 3BX

SCAZZOCCHIO, Dr C., Department of Biology, University of Essex, Colchester CO4 3SQ

SHIRE, Prof J. G. M., (Treasurer), Department of Biology, University of Essex, Colchester CO4 3SQ

SNOW, Dr M., MRC Mammalian Development Unit, University College London, Wolfson House, 4 Stephenson Way, London NW1 2HE 